\title{
Laparoscopic distal pancreatectomy in Italy: a systematic review and meta-analysis
}

\author{
Claudio Ricci, Riccardo Casadei, Enrico Lazzarini, Marielda D'Ambra, Salvatore Buscemi, \\ Carlo Alberto Pacilio, Giovanni Taffurelli and Francesco Minni
}

Bologna, Italy

\begin{abstract}
BACKGROUND: The use of laparoscopic distal pancreatectomy (LDP) increased in the past twenty years but the real diffusion of this technique is still unknown as well as the type of centers (high or low volume) in which this procedure is more frequently performed.
\end{abstract}

DATA SOURCE: A systematic review was performed to evaluate the frequency of LDP in Italy and to compare indications and results in high volume centers (HVCs) and in low volume centers (LVCs).

RESULTS: From 95 potentially relevant citations identified, only 5 studies were included. A total of 125 subjects were analyzed, of whom $95(76.0 \%)$ were from HVCs and $30(24.0 \%)$ from LVCs. The mean number of LDPs performed per year was 6.5. The mean number of patients who underwent LDP per year was 8.8 in HVCs and 3.0 in LVCs $(P<0.001)$. The most frequent lesions operated on in HVCs were cystic tumors $(62.1 \%, P<0.001)$ while, in LVCs, solid neoplasms $(76.7 \%, P<0.001)$. In HVCs, malignant neoplasms were treated with LDP less frequently than in LVCs $(\mathbf{1 7 . 9 \%}$ vs $\mathbf{5 0 . 0 \%}, \boldsymbol{P}<\mathbf{0 . 0 0 1})$. Splenectomy was performed for non-oncologic reason frequenter in HVCs than in LVCs $\mathbf{7 0 . 2 \%}$ vs $25.0 \%, P=0.004)$. The length of stay was shorter in HVCs than in LVCs $(7.5$ vs $11.3, P<0.001)$. No differences were found regarding age, gender, ductal adenocarcinoma treated, operative time, conversion, morbidity, postoperative pancreatic fistula, reoperation and margin status.

Author Affiliations: Dipartimento di Scienze Mediche e Chirurgiche (DIMEC), Alma Mater Studiorum, Università di Bologna, Policlinico S.Orsola-Malpighi, Bologna, Italy (Ricci C, Casadei R, Lazzarini E, D'Ambra M, Buscemi S, Pacilio CA, Taffurelli G and Minni F)

Corresponding Author: Claudio Ricci, MD, Dipartimento di Scienze Mediche e Chirurgiche, Chirurgia Generale-Minni, Alma Mater Studiorum, Università di Bologna, Policlinico S.Orsola-Malpighi, Via Massarenti n.9, 40138 Bologna, Italy (Tel: +39-51-341541; Fax: +39-51-341483; Email: claudiochir@gmail.com)

(C) 2014, Hepatobiliary Pancreat Dis Int. All rights reserved.

doi: 10.1016/S1499-3872(14)60297-6

Published online September 25, 2014.
CONCLUSIONS: LDPs were frequently performed in Italy. The "HVC approach" is characterized by a careful selection of patients undergoing LDP. The "LVC approach" is based on the hypothesis that LDPs are equivalent both in short-term and long-term results to laparotomic approach. These data are not conclusive and they point out the need for a national register of laparoscopic pancreatectomy.

(Hepatobiliary Pancreat Dis Int 2014;13:458-463)

KEY WORDS: pancreatic neoplasms; laparoscopic distal pancreatectomy; pancreatic surgery

\section{Introduction}

$\mathrm{T}$ The use of laparoscopic distal pancreatectomy (LDP) has increased in the past twenty years. ${ }^{[1]}$ Recent systematic reviews and meta-analyse ${ }^{[2-5]}$ have demonstrated the safety and feasibility of LDP for benign and malignant pancreatic lesions and have reported postoperative outcome advantages with respect to an open approach.

Despite the clinical benefit reported, LDP has not yet been considered the gold standard in clinical practice, and the exact utilization of the laparoscopic approach is still unknown. Rosales-Velderrain et $\mathrm{al}^{[6]}$ have recently reported that, in the United States, the use of LDP for benign and malignant body/tail pancreatic lesions is low, accounting for only $15 \%-27 \%$ of all distal pancreatectomies. Data regarding the Italian scenario are lacking even if at the 45th Annual Meeting of the European Pancreatic Club, Balzano et $\mathrm{al}^{[7]}$ reported a brief description regarding the diffusion of the laparoscopic technique for distal pancreatectomy in Italy. Our study involved a systematic review and the pooled analysis of LDP in Italy. The study aimed to evaluate the frequency of LDP and to compare the indications and results in high volume centers (HVCs) and in low volume centers (LVCs). 


\section{Methods}

\section{Study selection}

A systematic literature search was conducted using EMBASE, MEDLINE, the Cochrane Library, Scopus, the ISI-Web of Science and PubMed databases in order to identify all studies published up to 2013 regarding LDP in Italy. The search terms used MeSH and non-controlled vocabulary terms without MeSH. The search terms were used in logical combinations such as "distal pancreatectomy" OR "left pancreatectomy" OR "pancreatectomy" AND "laparoscopy" OR "laparoscopic" AND "Italy". The related articles found were used to broaden the search, and all abstracts, studies and citations obtained were reviewed. In addition, the references of all the studies included were screened for any potentially relevant studies. The search was conducted from January 1996 to July 2013.

\section{Inclusion and exclusion criteria}

All studies written in English which reported LDP in an Italian institution, case series or case-control with at least ten patients were included. Finally, if two studies were reported by the same institution (and/or authors), either the study with the larger sample size or the one of higher quality was included.

Studies which failed to fulfill the inclusion criteria were excluded. In addition, the following criteria were used to exclude studies: 1) studies without adequate data; 2) case-reports, reviews, guidelines, letters to editor and abstracts without a full text. All of the studies enrolled were published from 2008 to 2013.

\section{Data extraction}

Each study was evaluated by two independent reviewers (Ricci C and Lazzarini E) for inclusion or exclusion from the review using the data included in the abstract. The following data were extracted from each study: title, authors, year of publication, journal of publication, characteristics of the study population, study design, age, male/female ratio, pancreatic surgery volume, indications for surgery, overall distal pancreatectomy, LDP, type of operation (LDP with or without splenectomy), operative time, conversion rate, perioperative outcomes, status of resection margin (R0/1/2) and number of lymph nodes harvested. The choice of the articles included in this review was adherent to the quality of reporting of meta-analyses (QUOROM) statement ${ }^{[8]}$ and a QUOROM flow chart was also obtained in order to allow the transparency of the conclusions drawn by the authors.

\section{Outcome of interest and definitions}

The aims of this review were to identify the frequency of LDP in Italy and to compare the results reported in HVCs and LVCs. The primary endpoint was the number of LDPs performed per year. The secondary endpoints were: surgical indications, operative time, conversion rate, splenectomy expected/performed, postoperative morbidity, postoperative pancreatic fistula, length of stay, reoperation rate and margin status.

The volume of the center was defined according to the report by Gouma et al. ${ }^{[9]}$ The operative time was defined as the interval from skin incision to suture. The postoperative morbidity rate included all complications after surgery up to the day of discharge; they were classified according to the Clavien-Dindo classification. ${ }^{[10]}$ A postoperative pancreatic fistula was defined according to the criteria of the International Study Group on Pancreatic Fistula. ${ }^{[1]}$ Reoperation was defined as any surgical procedure performed in the first 30 postoperative days or before discharge from the hospital. The length of stay was defined as the interval from the day of surgery to the day of discharge.

\section{Statistical analysis}

Data were analyzed on an intention-to-treat basis where possible. All categorical variables were reported as frequency and percentage or as a ratio while the continuous variables were described as mean and standard deviation. To calculate the mean and standard deviation in studies which presented median and range, we used a dedicated statistical algorithm. ${ }^{[12]}$ The pooled data extracted from HVC and LVC series were analyzed. The data were analyzed only when they were extracted from at least three different studies. Dichotomous variables were analyzed using the odds ratio (OR), which represented the odds of an event occurring in HVCs or LVCs. An OR>1 indicated that the event was more likely in an HVC and the point estimate of the OR was considered statistically significant when $P<0.05$. Continuous variables were analyzed using weighted mean difference (WMD), indicating the difference between the two types of centers while accounting for the sample size. The statistical analysis was carried out using Review Manager Version 5.2 (The Cochrane Collaboration, Software Update, Oxford, London, UK).

\section{Results}

\section{Selected studies}

The results of the systematic search of the literature in accordance with the QUOROM statement are shown in Figure. Ninety-five potentially relevant citations were identified by a search of the literature published up to 
July 26, 2013. Forty-four papers were defined duplicate publications according to their titles. Of the remaining 51 references, 14 were excluded by evaluating their abstracts because they were either not written in English or contained data not pertinent to our endpoints, 28 were excluded because they were case reports, guidelines, reviews or letters to editor. Nine articles were reviewed as full texts. Of them, 2 were excluded because they had potentially redundant data, reporting data from the same institution and authors, and two articles were excluded because they contained not-extractable data. Finally, 5 studies ${ }^{[13-17]}$ were included in the metaanalysis (Fig.). On review of the data extraction, there was $100 \%$ agreement between the two reviewers. The characteristics of the studies selected are summarized

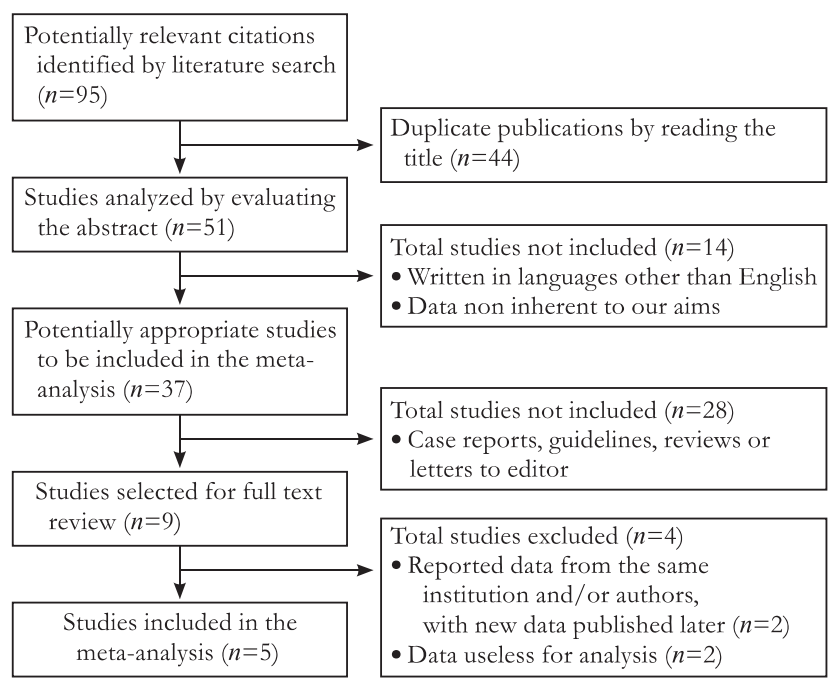

Fig. Quality of reporting meta-analysis statement. in Tables 1 and 2. All studies included reported similar exclusion criteria for laparoscopy as well as severe cardiopulmonary dysfunction or encasement of the mesenteric-portal vein or the superior mesenteric artery. All studies had recently been published (2008 or later) and involved at least 10 patients. In a total of 125 subjects analyzed, $95(76.0 \%)$ were from three HVCs and $30(24.0 \%)$ from two LVCs. In all single center studies, 1 study was prospective, 4 were retrospective; 2 were case series, and 3 were case-control studies.

\section{Pooled data}

The mean number of LDPs performed per year was 6.5 ; data on the number of LDP/total distal pancreatectomies were extracted from only two studies;

Table 1. Italian series of LDP included in the study

\begin{tabular}{|c|c|c|c|c|c|}
\hline Studies & $n$ & Study design & HVC & $\begin{array}{r}\mathrm{LDP} / \\
\text { year }\end{array}$ & $\begin{array}{l}\text { LDP/total } \\
\text { DP }\end{array}$ \\
\hline Pugliese et al ${ }^{[13]}$ & 14 & $\begin{array}{l}\text { Retrospective, } \\
\text { case series }\end{array}$ & No & 2.8 & - \\
\hline Casadei et al ${ }^{[14]}$ & 22 & $\begin{array}{c}\text { Retrospective, } \\
\text { case-control }\end{array}$ & Yes & 5.5 & - \\
\hline Butturini et a ${ }^{[15]}$ & 43 & $\begin{array}{c}\text { Retrospective, } \\
\text { case-control }\end{array}$ & Yes & 6.1 & $\begin{array}{l}43 / 116 \\
(37.1 \%)\end{array}$ \\
\hline Limongelli et a ${ }^{[16]}$ & 16 & $\begin{array}{c}\text { Retrospective, } \\
\text { case-control }\end{array}$ & No & 3.2 & $\begin{array}{l}16 / 28 \\
(57.1 \%)\end{array}$ \\
\hline Braga et a $\mathrm{l}^{[17]}$ & 30 & $\begin{array}{l}\text { Prospective, } \\
\text { case series }\end{array}$ & Yes & 15.0 & - \\
\hline Total & 125 & & & 6.5 & $\begin{array}{l}59 / 144 \\
(41.0 \%)\end{array}$ \\
\hline
\end{tabular}

-: not-extractable data. HVC: high volume center; LDP: laparoscopic distal pancrentectomy.

Table 2. Demographics, and clinical, surgical and pathological data extracted from the included studies $(n, \%)$

\begin{tabular}{|c|c|c|c|c|c|c|c|c|c|c|c|c|c|}
\hline \multirow[b]{2}{*}{ Studies } & \multirow[b]{2}{*}{ Age $(y r)$} & \multirow[b]{2}{*}{$\mathrm{M} / \mathrm{F}$} & \multicolumn{2}{|c|}{ Type of lesion } & \multirow[b]{2}{*}{ OT (min) } & \multirow{2}{*}{$\begin{array}{l}\text { Splenectomy } \\
\text { expected/ } \\
\text { performed }\end{array}$} & \multirow{2}{*}{$\begin{array}{c}\text { Conv } \\
\text { rate }\end{array}$} & \multirow[b]{2}{*}{$\begin{array}{l}\text { Morb } \\
\text { rate }\end{array}$} & \multirow[b]{2}{*}{$\begin{array}{l}\text { POPF } \\
\text { rate }\end{array}$} & \multirow[b]{2}{*}{$\begin{array}{l}\text { Reop } \\
\text { rate }\end{array}$} & \multirow[b]{2}{*}{$\begin{array}{r}\text { LOS } \\
\text { (d) }\end{array}$} & \multirow[b]{2}{*}{ R1 } & \multirow{2}{*}{$\begin{array}{l}\text { Lymph } \\
\text { node } \\
\text { harvested }\end{array}$} \\
\hline & & & $\begin{array}{l}\text { Malignant/ } \\
\text { total }\end{array}$ & $\begin{array}{l}\text { PDAC/ } \\
\text { total }\end{array}$ & & & & & & & & & \\
\hline Pugliese et al ${ }^{[13]}$ & $60 \pm 5$ & 0.27 & $\begin{array}{l}9 / 14 \\
(64.3)\end{array}$ & $\begin{array}{l}5 / 14 \\
(35.7)\end{array}$ & $227 \pm 24$ & 9/9 (100) & $\begin{array}{l}5 / 14 \\
(35.7)\end{array}$ & $\begin{array}{l}5 / 14 \\
(35.7)\end{array}$ & $\begin{array}{l}5 / 14 \\
(35.7)\end{array}$ & $\begin{array}{r}0 / 14 \\
(0)\end{array}$ & $17 \pm 8$ & $\begin{array}{c}0 / 9 \\
(0)\end{array}$ & - \\
\hline Casadei et al ${ }^{[14]}$ & $59 \pm 16.2$ & 0.22 & $\begin{array}{l}2 / 22 \\
(9.1)\end{array}$ & $\begin{array}{l}0 / 22 \\
(0)\end{array}$ & $225 \pm 83$ & 2/18 (11.1) & $\begin{array}{l}0 / 22 \\
(0)\end{array}$ & $\begin{array}{l}6 / 22 \\
(27.3)\end{array}$ & $\begin{array}{l}2 / 22 \\
(9.1)\end{array}$ & $\begin{array}{r}0 / 22 \\
(0)\end{array}$ & $8 \pm 1.3$ & $\begin{array}{c}0 / 2 \\
(0)\end{array}$ & - \\
\hline Butturini et al $^{[15]}$ & - & 0.23 & $\begin{array}{l}2 / 43 \\
(4.7)\end{array}$ & $\begin{array}{l}0 / 43 \\
(0)\end{array}$ & - & $2 / 24(8.3)$ & $\begin{array}{l}0 / 43 \\
(0)\end{array}$ & $\begin{array}{l}21 / 43 \\
(48.8)\end{array}$ & $\begin{array}{c}12 / 43 \\
(27.9)\end{array}$ & $\begin{array}{c}4 / 43 \\
(9.3)\end{array}$ & - & $\begin{array}{c}0 / 2 \\
(0)\end{array}$ & - \\
\hline Limongelli et al ${ }^{[16]}$ & $62.1 \pm 6.9$ & 0.60 & $\begin{array}{l}6 / 16 \\
(37.5)\end{array}$ & $\begin{array}{l}1 / 16 \\
(6.3)\end{array}$ & $204 \pm 31$ & $6 / 11(54.5)$ & $\begin{array}{l}1 / 16 \\
(6.3)\end{array}$ & $\begin{array}{l}4 / 16 \\
(25.0)\end{array}$ & $\begin{array}{l}3 / 16 \\
(18.8)\end{array}$ & $\begin{array}{r}0 / 16 \\
(0)\end{array}$ & $6.4 \pm 2.3$ & $\begin{array}{l}1 / 6 \\
(16.7)\end{array}$ & - \\
\hline Braga et al ${ }^{[17]}$ & $55.5 \pm 16.2$ & 0.67 & $\begin{array}{l}13 / 30 \\
(43.3)\end{array}$ & $\begin{array}{l}11 / 30 \\
(36.7)\end{array}$ & $209 \pm 66$ & $13 / 15(86.7)$ & $\begin{array}{l}7 / 30 \\
(23.3)\end{array}$ & $\begin{array}{l}14 / 30 \\
(46.7)\end{array}$ & $\begin{array}{l}12 / 30 \\
(40.0)\end{array}$ & $\begin{array}{r}0 / 30 \\
(0)\end{array}$ & $7.1 \pm 3.3$ & $\begin{array}{r}0 / 21 \\
(0)\end{array}$ & $15.5 \pm 9.2$ \\
\hline Total & $58.4 \pm 12.5$ & 0.36 & $\begin{array}{r}32 / 125 \\
(25.6)\end{array}$ & $\begin{array}{r}17 / 125 \\
(13.6)\end{array}$ & $215.4 \pm 58.1$ & $32 / 77$ (41.6) & $\begin{array}{r}13 / 125 \\
(10.4)\end{array}$ & $\begin{array}{r}50 / 125 \\
(40.0)\end{array}$ & $\begin{array}{r}34 / 125 \\
(27.2)\end{array}$ & $\begin{array}{r}4 / 125 \\
(3.2)\end{array}$ & $9 \pm 3.4$ & $\begin{array}{l}1 / 40 \\
(2.5)\end{array}$ & $15.5 \pm 9.2$ \\
\hline
\end{tabular}

-: not-extractable data; M: male; F: female; PDAC: pancreatic ductal adenocarcinoma; OT: operative time; Conv: conversion; Morb: morbidity; POPF: postoperative pancreatic fistula; Reop: reoperation; LOS: length of stay; R1: positive microscopic resection margin. 
in $41.0 \%(59 / 144)$ of the patients, a laparoscopic approach was used (Table 1). The demographics and clinical, surgical and pathological data are shown in Table 2. The mean age of the patients was 58.4 \pm 12.5 years (four studies) with a male/female ratio of 0.36 . LDP was performed more frequently for cystic lesions $(52.8 \%, 66 / 125)$ than for solid lesions $(47.2 \%$, $59 / 125$ ), giving a cystic/solid lesion ratio of 1.12 . LDP was done for malignant lesions in $25.6 \%$ of the patients, and only $13.6 \%$ of the patients had pancreatic ductal adenocarcinomas (PDACs). In all studies, patients with malignant neoplasms were involved, but only three centers systematically performed LDPs for body/tail resectable PDAC. The mean operative time was $215.4 \pm$ 58.1 minutes (four studies) with a conversion rate of $10.4 \%(13 / 125)$. LDP with splenectomy was performed in $61.6 \%(77 / 125)$ of the patients, whereas those performed for oncologic reasons accounted for $25.6 \%$ (32/125), with a splenectomy expected/performed ratio of 0.42 . The morbidity and postoperative pancreatic fistula rates were $40.0 \%(50 / 125)$ and $27.2 \%(34 / 125)$, respectively. The reoperation rate was $3.2 \%$ and the mean length of stay was $9 \pm 3.4$ days (four studies). R1 resections were rarely performed $(2.5 \%, 1 / 40)$. Only one study reported

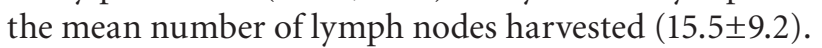

\section{Meta-analytic results}

The results of the comparison between LDP in HVCs and LVCs are shown in Table 3. The number of LDPs/total distal pancreatectomies and the number of lymph nodes harvested were not analyzed because these data were reported by only two studies and one study, respectively. The mean number of patients who underwent LDP per year was $8.8 \pm 5.3$ and $3.0 \pm 0.3$ in HVCs and LVCs, respectively, giving a WMD of 5.80 $(4.73,6.87 ; P<0.001)$. The age and gender of the patients were similar in the two types of centers with a WMD and OR of $-4.20(-9.11,0.71 ; P=0.09)$ and $0.79(0.32,1.95$; $P=0.61)$, respectively. The most frequent lesions operated on in HVCs were cystic tumors $(62.1 \%)$ giving an OR of $5.38(2.10,13.81 ; P<0.001)$ while, in LVCs, the lesions were solid neoplasms (76.7\%), giving an OR of 0.19 (0.07, $0.48 ; P<0.001)$. In HVCs, malignant neoplasms were treated with LDP less frequently than in LVCs $(17.9 \%$ vs $50.0 \%)$ corresponding to an OR of $0.22(0.09,0.53$; $P<0.001)$. The number of patients with PDACs who were treated was low in both HVCs and LVCs $(11.6 \%$ and $20.0 \% ; P=0.25)$. The operative time which was similar in both HVCs and LVCs resulted in a WMD of $1.00(-21.23,23.23 ; P=0.93)$. LDP with splenectomy was performed for oncologic reason more frequently in LVCs than in HVCs $(75.0 \%$ vs $29.8 \%$, respectively)
Table 3. Comparison between LDP in HCVs and LVCs

\begin{tabular}{|c|c|c|c|c|c|c|}
\hline Variables & $n$ & HVC & $n$ & LVC & $\begin{array}{l}\text { OR or WMD } \\
(95 \% \mathrm{CI})\end{array}$ & $P$ value \\
\hline LDPs/per year & 95 & $8.8 \pm 5.3$ & 30 & $3.0 \pm 0.3$ & $5.80(4.73,6.87)$ & $<0.001$ \\
\hline Male/total (\%) & 95 & $24(25.2)$ & 30 & $9(30.0)$ & $0.79(0.32,1.95)$ & 0.61 \\
\hline Age (yr) & 52 & $56.9 \pm 16.2$ & 30 & $61.1 \pm 6.1$ & $-4.20(-9.11,0.71)$ & 0.09 \\
\hline Cystic/total (\%) & 95 & $59(62.1)$ & 30 & $7(23.3)$ & $5.38(2.10,13.81)$ & $<0.001$ \\
\hline Solid/total (\%) & 95 & $36(37.9)$ & 30 & $23(76.7)$ & $0.19(0.07,0.48)$ & $<0.001$ \\
\hline $\begin{array}{l}\text { Malignant/total } \\
(\%)\end{array}$ & 95 & $17(17.9)$ & 30 & $15(50.0)$ & $0.22(0.09,0.53)$ & $<0.001$ \\
\hline PDAC/total & 95 & $11(11.6)$ & 30 & $6(20.0)$ & $0.52(0.18,1.56)$ & 0.25 \\
\hline OT (min) & 52 & $215 \pm 73$ & 30 & $214 \pm 28$ & $1.00(-21.23,23.23)$ & 0.93 \\
\hline $\begin{array}{l}\text { Conversion rate } \\
(\%)\end{array}$ & 95 & $7(7.4)$ & 30 & $6(20.0)$ & $0.32(0.10,1.04)$ & 0.06 \\
\hline $\begin{array}{l}\text { Morbidity rate } \\
(\%)\end{array}$ & 95 & $41(43.2)$ & 30 & $9(30.0)$ & $1.77(0.73,4.27)$ & 0.20 \\
\hline POPF rate $(\%)$ & 95 & $26(27.4)$ & 30 & $8(26.7)$ & $1.04(0.41,2.62)$ & 0.94 \\
\hline $\begin{array}{l}\text { Reoperation rate } \\
(\%)\end{array}$ & 95 & $4(4.2)$ & 30 & $0(0)$ & $3.00(0.16,57.34)$ & 0.47 \\
\hline $\operatorname{LOS}(\mathrm{d})$ & 52 & $7.5 \pm 2.4$ & 30 & $11.3 \pm 4.6$ & $-3.80(-5.57,-2.03)$ & $<0.001$ \\
\hline $\begin{array}{l}\text { Splenectomy } \\
\text { expected/ } \\
\text { performed }\end{array}$ & 57 & $17(29.8)$ & 20 & $15(75.0)$ & $0.14(0.04,0.45)$ & $<0.001$ \\
\hline $\mathrm{R} 1$ & 25 & $0(0)$ & 15 & $1(6.7)$ & $0.19(0.01,4.96)$ & 0.32 \\
\hline
\end{tabular}

HVC: high volume center; LVC: low volume center; OR: odds ratio; WMD: weighted mean difference; LDP: laparoscopic distal pancreatectomy; PDAC: pancreatic ductal adenocarcinoma; OT: operative time; POPF: postoperative pancreatic fistula; LOS: length of stay; R1: positive microscopic resection margin.

with an OR of $0.14(0.04,0.45 ; P<0.001)$. The conversion rate was lower in HVCs than in LVCs, but it was not statistically significant $(P=0.06)$. Pooled morbidity, postoperative pancreatic fistula and reoperation rates were similar in the two types of centers with ORs of 1.77 $(0.73,4.27 ; P=0.20), 1.04(0.41,2.62 ; P=0.94)$ and 3.00 $(0.16,57.34 ; P=0.47)$, respectively. The length of stay was statistically shorter in HVCs than in LVCs $(7.5 \pm 2.4$ vs $11.3 \pm 4.6)$ as shown by a WMD of $-3.80(-5.57,-2.03$; $P<0.001)$. There were no differences between the two types of centers regarding positive resection margins in malignant neoplasms ( $0 \%$ vs $6.7 \%)$ with an OR of 0.19 $(0.01,4.96 ; P=0.32)$.

\section{Discussion}

LDP has rapidly expanded its application over the last decade and, although randomized studies are lacking, recent meta-analyses ${ }^{[2-5]}$ have suggested that LDP was safe and effective as open distal pancreatectomy. Nevertheless, Rosales-Velderrain et $\mathrm{al}^{[6]}$ have reported that, in the United States, only a low percentage $(15 \%-27 \%)$ of patients with body/tail pancreatic tumors were subjected to 
LDP. To our knowledge, there are no data regarding the diffusion of LDP in Europe, especially in Italy. Moreover, there are no data regarding the different approach to LDP for pancreatic surgery in HVCs and LVCs.

Our systematic review included 5 studies on 3 HVCs and 2 LVCs. Data regarding the use of the laparoscopic approach were extracted from only 2 studies. The review showed that $41.0 \%$ of patients with body/tail pancreatic tumors underwent LDP. This result indicated good diffusion of the laparoscopic approach even if LDP was not always performed, probably because this approach was sometimes not indicated, for example in case of the presence of PDACs. The number of LDPs performed in Italy per center per year was 6.5 procedures. A pooled analysis showed that the mean number of patients treated every year with LDP was significantly higher in HVCs than in LVCs. These data first suggest that, in Italy, high volume pancreatic surgeons did not exclude the use of the laparoscopic approach in body/tail lesions. In fact, in HVCs, preoperative suspicion of malignancy did not exclude laparoscopic approach. However, we found that 2 out of 3 HVCs considered mini-invasive surgery systematically not suitable for PDAC treatment. Regarding the type of lesion, we did not find a clear prevalence of cystic or solid lesions in Italian laparoscopic series. However, there were some statistically significant differences in the types of lesions treated when we considered HVCs and LVCs separately. In HVCs, the most common indication for LDP was a cystic lesion, whereas, in LVCs, it was the presence of a solid neoplasm. Malignant lesions were treated in every study, accounting for $25.6 \%$ of all neoplasms, whereas $13.6 \%$ of the patients had PDACs. Nevertheless, in LVCs, a mini-invasive approach was carried out more frequently with respect to HVCs for malignant lesions, but the indication for patients with PDACs was similar. These data suggested that, in Italy, the laparoscopic approach was used with prudence in the absence of data regarding long-term results, at least in HVCs. This approach seems to be similar to those of other European countries as reported by Mabrut et $\mathrm{al}^{[18]}$ in a study of multicentric series. This study, which included all types of pancreatic laparoscopic resections, found that the most common indication was benign pancreatic disease and only $3.9 \%$ of patients were affected by PDACs. On the other hand, the scenario seems to be different, in the United States, LDPs have frequently been used for malignant neoplasms. However, Rosales-Velderrain et $\mathrm{al}^{[6]}$ reported that it is impossible to clearly extract the correlation between hospital volume and type of lesion. There was no difference in operative time in HVCs and LVCs in our study. This finding was dependent on the presence of skilled laparoscopic surgeons in both types of centers. The low expected/performed splenectomy ratio indicated that almost half of the splenectomies were performed for technical reasons. Moreover, we noted that the ratio was significantly lower in HVCs with respect to LVCs. This finding clearly demonstrates that the number of splenectomies for non-oncological reasons was higher in HVCs than in LVCs. There are various reasons which might explain this difference including higher oncological prudence in HVCs and/or the advanced laparoscopic expertise of LVC surgeons. In fact, as all things are considered, LVCs are advanced laparoscopic centers. ${ }^{[19,20]}$ The conversion rate was higher in LVCs than in HVCs, but in LVCs, solid and malignant lesions were frequently treated. Pooled morbidity, postoperative pancreatic fistula and reoperation rates were similar in the two types of centers as has already been reported in the United States experience. The length of stay was shorter in HVCs than in LVCs as described by Balzano et $\mathrm{l}^{[21]}$ for laparotomic pancreatic surgery. Furthermore, the R1 resection rate was similar in HVCs and LVCs.

In conclusion, despite the small sample size analyzed, our study showed some differences between LDPs performed in HVCs and those performed in LVCs in Italy. In our opinion, these differences could reflect two different approaches. First, the "HVC approach", which represents the point of view of pancreatic surgeons, characterized by a careful selection of patients undergoing LDP. Second, the "LVC approach", the more technical approach, was used by skilled laparoscopic surgeons. This point of view hypothesizes equivalent oncological results of laparotomic procedures even if there is no evidence in the literature. These data are not conclusive and they point out the need for a national register of laparoscopic pancreatectomies which could allow better analyses on larger samples of patients.

Contributors: RC and CR proposed the study. RC and LE performed data acquisition and quality control of data and algorithms. RC, DM, BS, PCA and TG analyzed the data. RC wrote the first draft. $\mathrm{CR}$ and $\mathrm{MF}$ revised the manuscript. $\mathrm{RC}$ is the guarantor.

Funding: None.

Ethical approval: Not needed.

Competing interest: No benefits in any form have been received or will be received from a commercial party related directly or indirectly to the subject of this article.

\section{References}

1 Ammori BJ, Ayiomamitis GD. Laparoscopic pancreaticoduodenectomy and distal pancreatectomy: a UK experience and a systematic review of the literature. Surg Endosc 2011;25:2084- 
2099.

2 Jin T, Altaf K, Xiong JJ, Huang W, Javed MA, Mai G, et al. A systematic review and meta-analysis of studies comparing laparoscopic and open distal pancreatectomy. HPB (Oxford) 2012;14:711-724.

3 Pericleous S, Middleton N, McKay SC, Bowers KA, Hutchins RR. Systematic review and meta-analysis of casematched studies comparing open and laparoscopic distal pancreatectomy: is it a safe procedure? Pancreas 2012;41:9931000.

4 Venkat R, Edil BH, Schulick RD, Lidor AO, Makary MA, Wolfgang CL. Laparoscopic distal pancreatectomy is associated with significantly less overall morbidity compared to the open technique: a systematic review and meta-analysis. Ann Surg 2012;255:1048-1059.

5 Jusoh AC, Ammori BJ. Laparoscopic versus open distal pancreatectomy: a systematic review of comparative studies. Surg Endosc 2012;26:904-913.

6 Rosales-Velderrain A, Bowers SP, Goldberg RF, Clarke TM, Buchanan MA, Stauffer JA, et al. National trends in resection of the distal pancreas. World J Gastroenterol 2012;18:43424349.

7 Balzano G, Bassi C, De Lio N, Giovanni C, Francesco M, Angiolini MR, et al. Perioperative outcome of minimally invasive spleen-preserving distal pancreatectomy: Results of a multicenter survey in Italy. Pancreatology 2013;13:S3.

8 Moher D, Cook DJ, Eastwood S, Olkin I, Rennie D, Stroup DF. Improving the quality of reports of meta-analyses of randomised controlled trials: the QUOROM statement. Quality of Reporting of Meta-analyses. Lancet 1999;354:1896-1900.

9 Gouma DJ, van Geenen RC, van Gulik TM, de Haan RJ, de Wit LT, Busch OR, et al. Rates of complications and death after pancreaticoduodenectomy: risk factors and the impact of hospital volume. Ann Surg 2000;232:786-795.

10 Dindo D, Demartines N, Clavien PA. Classification of surgical complications: a new proposal with evaluation in a cohort of 6336 patients and results of a survey. Ann Surg 2004;240:205-213.

11 Bassi C, Dervenis C, Butturini G, Fingerhut A, Yeo C, Izbicki J, et al. Postoperative pancreatic fistula: an international study group (ISGPF) definition. Surgery 2005;138:8-13.

12 Hozo SP, Djulbegovic B, Hozo I. Estimating the mean and variance from the median, range, and the size of a sample. BMC Med Res Methodol 2005;5:13.

13 Pugliese R, Maggioni D, Sansonna F, Scandroglio I, Forgione A, Boniardi $\mathrm{M}$, et al. Laparoscopic distal pancreatectomy: a retrospective review of 14 cases. Surg Laparosc Endosc Percutan Tech 2008;18:254-259.

14 Casadei R, Ricci C, D'Ambra M, Marrano N, Alagna V, Rega $\mathrm{D}$, et al. Laparoscopic versus open distal pancreatectomy in pancreatic tumours: a case-control study. Updates Surg 2010;62:171-174.

15 Butturini G, Inama M, Malleo G, Manfredi R, Melotti GL, Piccoli M, et al. Perioperative and long-term results of laparoscopic spleen-preserving distal pancreatectomy with or without splenic vessels conservation: a retrospective analysis. J Surg Oncol 2012;105:387-392.

16 Limongelli P, Belli A, Russo G, Cioffi L, D'Agostino A, Fantini C, et al. Laparoscopic and open surgical treatment of left-sided pancreatic lesions: clinical outcomes and costeffectiveness analysis. Surg Endosc 2012;26:1830-1836.

17 Braga M, Ridolfi C, Balzano G, Castoldi R, Pecorelli N, Di Carlo V. Learning curve for laparoscopic distal pancreatectomy in a high-volume hospital. Updates Surg 2012;64:179-183.

18 Mabrut JY, Fernandez-Cruz L, Azagra JS, Bassi C, Delvaux $\mathrm{G}$, Weerts J, et al. Laparoscopic pancreatic resection: results of a multicenter European study of 127 patients. Surgery 2005;137:597-605.

19 Pugliese R, Di Lernia S, Sansonna F, Maggioni D, Ferrari GC, Magistro C, et al. Laparoscopic resection for rectal adenocarcinoma. Eur J Surg Oncol 2009;35:497-503.

20 Belli G, Fantini C, Belli A, Limongelli P. Laparoscopic liver resection for hepatocellular carcinoma in cirrhosis: longterm outcomes. Dig Surg 2011;28:134-140.

21 Balzano G, Zerbi A, Capretti G, Rocchetti S, Capitanio V, Di Carlo V. Effect of hospital volume on outcome of pancreaticoduodenectomy in Italy. Br J Surg 2008;95:357-362.

Received February 11, 2014 Accepted after revision June 4, 2014 